\title{
GROWTH INHIBITION AND MORPHOLOGICAL ALTERATIONS OF TRICHOPHYTON RUBRUM INDUCED BY ESSENTIAL OIL FROM CYMBOPOGON WINTERIANUS JOWITT EX BOR
}

\section{Fillipe de Oliveira Pereira ${ }^{*}$, Paulo Alves Wanderley ${ }^{2}$, Fernando Antônio Cavalcanti Viana ${ }^{3}$, Rita Baltazar de Lima ${ }^{4}$, Frederico Barbosa de Sousa ${ }^{5}$, Edeltrudes de Oliveira Lima ${ }^{1}$.}

${ }^{1}$ Laboratório de Micologia, Departamento de Ciências Farmacêuticas, Centro de Ciências da Saúde, Universidade Federal da Paraíba, João Pessoa, PB, Brasil; ${ }^{2}$ Departamento de Agricultura, Centro de Formação de Tecnólogos, Universidade Federal da Paraíba, Bananeiras, PB, Brasil; ${ }^{3}$ Horto de Plantas Medicinais, Laboratório de Tecnologia Farmacêutica, Centro de Ciências da Saúde, Universidade Federal da Paraíba, João Pessoa, PB, Brasil; ${ }^{4}$ Laboratório de Botânica, Departamento de Sistemática e Ecologia, Centro de Ciências Exatas e da Natureza, Universidade Federal da Paraíba, João Pessoa, PB, Brasil; ${ }^{5}$ Laboratório de Microscopia e Imagem Biológica, Centro de Ciências da Saúde, Universidade Federal da Paraíba, João Pessoa, PB, Brasil;

\begin{abstract}
Trichophyton rubrum is one of the most common fungi causer of dermatophytosis, mycosis that affect humans and animals around the world. Researches aiming new products with antifungal activity become necessary to overcome difficulties on treatment of these infections. Accordingly, this study aimed to investigate the antifungal activity of essential oil from Cymbopogon winterianus against the dermatophyte $T$. rubrum. The antifungal screening was performed by solid medium diffusion method with 16 T. rubrum strains, minimum inhibitory concentration (MIC) and minimum fungicide concentration (MFC) were determined using the microdilution method. The effects on mycelial dry weight and morphology were also observed. Screening showed essential oil in natura inhibited all the tested strains, with inhibition zones between 24-28 mm diameter. $\mathrm{MIC}_{50}$ and $\mathrm{MIC}_{90}$ values of the essential oil were $312 \mu \mathrm{g} / \mathrm{mL}$ for nearly all the essayed strains $\left(93.75 \%\right.$ ) while the $\mathrm{MFC}_{50}$ and $\mathrm{MFC}_{90}$ values were about eight times higher than MIC for all tested strains. All tested essential oil concentrations managed to inhibit strongly the mycelium development. Main morphological changes on the fungal strains observed under light microscopy, which were provided by the essential oil include loss of conidiation, alterations concerning form and pigmentation of hyphae. In the oil presence, colonies showed folds, cream color and slightly darker than the control, pigment production was absent on the reverse and with evident folds. It is concluded that $C$. winterianus essential oil showed activity against T. rubrum. Therefore, it could be known as potential antifungal compound especially for protection against dermatophytosis.
\end{abstract}

Key words: Trichophyton, essential oil, Cymbopogon.

\footnotetext{
*Corresponding Author. Mailing address: Laboratório de Micologia, Departamento de Ciências Farmacêuticas, Centro de Ciências da Saúde, Universidade Federal da Paraíba. 58051-900 Campus Universitário I, Castelo Branco I, João Pessoa, Paraíba, Brasil..; Tel.: 83-3216-7026/ 83-8756-6652 Fax: 83-3216-7094.; Email: fillipefop@yahoo.com.br
} 


\section{INTRODUCTION}

Dermatophytes are a fungi group with capacity to invade keratinized tissues (skin, hair and nails) of humans and other animals producing dermatophytosis. The incidence of this infection has increased over recent years, particularly in immunocompromissed patients and it is considered the most common and widespread infectious disease worldwide (39, 41).

Trichophyton rubrum is a worldwide pathogen causing various superficial infections, accounting for at least $60 \%$ of dermatophytosis, such as tinea capitis, tinea corporis, tinea inguinalis, tinea manuum, tinea unguium and tinea pedis (15). Researchers from South and North America and Europe mention this microorganism as one of the most commonly isolated in cases of dermatophytosis in these regions and with recognized local resistance to therapy $(25,30,31,40)$. In Brazil, it also remains the most frequently isolated $(7,20)$.

Dermatophytosis treatment has been cause of great concern among researchers around the world. This fact is justified by increasing prevalence of these diseases in the world, extensive use of antifungal agents and consequent emergence of fungal strains resistant to the main drugs commonly used in clinical therapy (24). For overcome this problem, the development of new antifungal products is necessary. In this situation, interest in plants with antifungal properties has increased as a consequence of current problems associated with the antifungal therapy. Since antiquity, medicinal plants have been used to treat common infectious diseases and the essential oils of these plants have been widely used in the treatment of infectious pathologies in many body parts including skin $(23,29)$.

Cymbopogon winterianus Jowitt ex Bor (Poaceae) popularly known as "citronella" or "java citronella", is a perennial herb which cultivated in India and Brazil. This medicinal plant is used by population as repellent, antimycotic and acaricide activities (26).
This study was carried out aiming to investigate the antifungal activity of the essential oil of $C$. winterianus from Bananeiras city in Paraiba state-Brazil, analyzing its effects on growth and morphology of some T. rubrum strains known as one of the most important species causing dermatophytosis.

\section{MATERIAL AND METHODS}

\section{Plant material}

Leaves of $C$. winterianus were collected from the Formation Center for Technicians in Federal University of Paraiba (campus IV), Bananeiras city, Paraiba state-Brazil, in February 2007. Botanical identification of the plant was obtained and a voucher sample (JPB 41387) has been deposited at the Herbarium Professor Lauro Pires Xavier, in the Federal University of Paraiba.

\section{Essential oil}

Fresh leaves of $C$. winterianus were cut into pieces and subjected to water-distillation using a Clevenger apparatus. The essential oil obtained (density $=0.8790 \mathrm{~g} / \mathrm{mL}$ ) was kept in amber bottle flask and maintained at temperature lower than $4^{\circ} \mathrm{C}$. The oil emulsion used in antifungal essays were obtained according to following procedure: $34 \mu \mathrm{L}$ of essential oil, $10 \mu \mathrm{L}$ of tween 80 and q.s.f. $3 \mathrm{~mL}$ of sterile distilled water were added in a sterile tube and shaken for 3 minutes using a vortex instrument, thus obtaining a stock emulsion with $10000 \mu \mathrm{g} / \mathrm{mL}$ final concentration. Seriate dilutions were performed in proportion of two in order to obtain emulsions from $5000-5$ $\mu \mathrm{g} / \mathrm{mL}$.

\section{Test fungal strains}

Dermatophytes used in antifungal essays were obtained from the collection of Mycology Laboratory (LM), Pharmaceutical Science Department, Health Science Center, Federal University of Paraiba. They included these following 15 T. rubrum strains: LM63, LM98, LM130, LM222, LM309, 
LM333, LM422, LM600, LM 629, LM640, LM710, LM713, LM720, LM722 and LM730. Quality control T. rubrum strain (ATCC 1683) was also included. Fungi were maintained in potato dextrose agar (PDA) (Difco ${ }^{\circledR}$ ) at $28^{\circ} \mathrm{C}$ and $4^{\circ} \mathrm{C}$ until tests procedures.

\section{Inoculum preparation}

Stock inoculums suspensions of $T$. rubrum strains were prepared from 10-day culture in PDA at $28^{\circ} \mathrm{C}$ to induce sporulation. Fungal colonies were covered with $5 \mathrm{~mL}$ of sterile saline solution $(\mathrm{NaCl} 0,85 \% \mathrm{w} / \mathrm{v})$, the surface gently scraped with a sterile loop and this resultant mixture of fungal units was transferred to a sterile tube. The turbidity of the final inoculum was standardized according to McFarland scale 0.5 tube and adjusted for presenting the fungal population of $10^{6}$ colony former units (CFU). The confirmation of the inoculum quantification was made by plating $0.01 \mathrm{ml}$ of inoculum suspension in Sabouraud dextrose agar (SDA). The plates were incubated at $28^{\circ} \mathrm{C}$ and were examined daily for the presence of fungal colonies which were counted as soon as growth became visible $(3,18,33)$.

\section{Antifungal activity screening}

Solid medium diffusion method using filter paper discs was used for antifungal activity screening as preliminary test for evaluating potential activity of the essential oil $(1,18)$. Sterile Sabouraud dextrose agar (SDA) $\left(\right.$ Difco $^{\circledR}$ ) was prepared and distributed uniformly into sterile petri plates, where $1 \mathrm{~mL}$ of the fungal suspension was previously inoculated. Afterwards, filter paper discs (diameter $6 \mathrm{~mm}$ ) were soaked with $20 \mu \mathrm{l}$ of essential oil and placed on the surface of the inoculated agar. Plates have been incubated at $28^{\circ} \mathrm{C}$ for 8 days. At the end of the incubation period, fungal growth inhibition zone diameter was measured and expressed in millimeters. It was considered positive that antifungal activity when the geometric mean values of growth inhibition zone in two independent essays were equal or higher than $10 \mathrm{~mm}$ diameter
$(19,38)$

\section{Determination of minimum inhibitory concentration (MIC)}

The MIC values were determined for the fungi strains which were sensitive to the essential oil in solid medium diffusion assay. Broth microdilution bioassay was used to determine the MIC of $C$. winterianus essential oil $(22,32)$. For this, it was used 96-well plates (flatted bottom) and cap. The 96-well plates were prepared by dispensing $100 \mu \mathrm{L}$ of doubled concentrated Sabouraud dextrose broth (SDB) (Difco ${ }^{\circledR}$ ) into each well. $100 \mu \mathrm{L}$ from the stock emulsion of essential oil was added into the first wells. Then, $100 \mu \mathrm{L}$ from their serial dilutions were transferred into consecutives wells, excluding the last ones. The last well contained $100 \mu \mathrm{L}$ of broth inoculated with fungal inoculum to confirm the cell viability (viability control). At the same way positive control was carried out with standard antifungal using Ketoconazole $\left(\right.$ Sigma-Aldrich $\left.{ }^{\circledR}\right)$. In both cases, the highest concentration $(5000 \mu \mathrm{g} / \mathrm{mL})$ was added into the first wells and the lowest concentration $(5 \mu \mathrm{g} / \mathrm{mL})$ was added into the penultimate wells. Sensitivity control of the essayed strains to the tween 80 without essential oil was carried out by microdilution. A 100 $\mu \mathrm{L}$ of $5 \%$ tween 80 in broth was added into wells and $10 \mu \mathrm{L}$ of fungal suspensions were inoculated into each respective well. Also, a sterility control was performed to verify whether the broth used in antifungal essay was contaminated before test procedures. For this, $100 \mu \mathrm{L}$ of broth was dispensed into a well, without both essential oil and inoculum.

All plates were aseptically sealed followed by mixing on plate shaker (300 rpm) for 30 seconds, incubated at $28^{\circ} \mathrm{C}$ being read after 5 days incubation. The MIC values were determined by visual inspection of the growth inhibition of each well compared with that of the control (without drugs) well. MIC was defined as the lowest essential oil concentration able to inhibit $100 \%$ the fungal growth. The test was performed in duplicate and the geometric mean values were calculated. $\mathrm{MIC}_{50}$ values were interpreted as the MIC which $50 \%$ of the 
isolates were inhibited and $\mathrm{MIC}_{90}$ is the MIC at which $90 \%$ of the isolates were inhibited (34).

\section{Determination of the minimum fungicide concentration (MFC)}

MFC was determined the microdilution method to verify if the inhibition was reversible or permanent $(12,28)$. Aliquot of $20 \mu \mathrm{L}$ from the wells that did not show growth in MIC procedure was transferred to 96-well plates previously prepared with $100 \mu \mathrm{L}$ of SDB. The plates were aseptically sealed followed by mixing on plate shaker $(300 \mathrm{rpm})$ for 30 seconds, incubated at $28^{\circ} \mathrm{C}$ and being read 5 days of incubation. The test was performed in duplicate and the geometric mean values were calculated. MFC was defined as the lowest essential oil concentration in which no visible growth occurred when subcultured on the 96-well plates contained broth without antifungical products.

\section{Effects on mycelial growth}

Analysis of the interference of the essential oil of $C$. winterianus on mycelial growth was performed by determining the dry mycelial weight of $T$. rubrum ATCC 1683 (28, 35). For determination of the oil effects on the dry weight, flasks containing $2500,625,312$ and $156 \mu \mathrm{g} / \mathrm{mL}$ of essential oil in SDB medium were inoculated with suspension of test $T$. rubrum strains. In the correspondent control, the same amount of essential oil was replaced by distilled water. The system was incubated at $28^{\circ} \mathrm{C}$ for 15 days. From the sixth day of incubation, micelia dry weight was determined every 3 days. Flasks containing mycelia were filtered through Whatman filter no. 1 (particle retention: $11 \mu \mathrm{m}$ ) and then washed with distilled water. The mycelia were dried at $60^{\circ} \mathrm{C}$ for $6 \mathrm{~h}$ and then at $40^{\circ} \mathrm{C}$ over night. The filter paper containing dry mycelia from two independent essays were weighed and the mean values obtained. Percent growth inhibition based on the dry weight, at each time of analysis, was calculated as:

[(control weight - sample weight) x 100] / Control weight.

\section{Microscopic study of fungal morphology}

The evaluation on the micromorphological alterations caused by the essential oil of $C$. winterianus in $T$. rubrum ATCC 1683 was performed in duplicate by the slide culture technique. At first, a SDA block containing the essential oil $(78,156,312 \mu \mathrm{L} / \mathrm{mL})$ was transferred to the center of a glass slide in a Petri dish with a piece of filter paper. Subsequently, a mycelium sample was taken from the periphery of a 10-daysold fungal colony grown on PDA and inoculated onto the center of the sides of the agar medium block. About $1.5 \mathrm{~mL}$ of sterile water was placed in the Petri dish bottom and incubated at $28^{\circ} \mathrm{C}$ for 5 days. After incubation, slides with reproductive structures were fixed in lacto-phenol-cotton blue stain and observed under the optical microscope (Olympus ${ }^{\circledR}$ model $\mathrm{CH}$ 30 ) at 400x to examine morphological abnormalities. Structural changes observed in optical microscopy in test essays were recorded and compared with the normal growth found in the control experiment. Control essay without essential oil was tested in the same way $(14,16)$.

\section{Macroscopic study of fungal morphology}

The evaluation on the macromorphological alterations caused by the essential oil of $C$. winterianus was performed by macroscopic examination of cultures of T. rubrum ATCC 1683 in duplicate. Petri dishes were initially prepared with $15 \mathrm{~mL}$ of medium SDA added of 78, 156 and $312 \mu \mathrm{g} / \mathrm{mL}$ the essential oil and the whole system was homogenized. After solidification of the culture medium, fungi were inoculated onto each agar surface. Control essay without essential oil was tested in the same way. After assembling the dishes, the whole system was incubated at $28{ }^{\circ} \mathrm{C}$ for 10 days. Afterwards, analysis were finally performed based on the visual observation of colonies of control and test experiments characterizing them by appearance, texture and surface color, in addition to aspects of colonies' color reverse $(1,9)$.

\section{Statistical analysis}

Statistical analysis for the study of the effects of essential 
oil on mycelial weight, was performed to determine statistically significant differences $(\mathrm{P}<0.05)$ employing analysis of variance (one-way ANOVA) using Kruskal-Wallis test followed by Dunn post-test. For this, the implementation of statistical analysis was performed using GraphPad Prism version 4.03 for Windows, San Diego, California, USA.

\section{RESULTS AND DISCUSSION}

Results of antifungal activity of $C$. winterianus essential oil on T. rubrum strains are shown in Table 1. The essential oil in natura had inhibitory effect on all strains tested with inhibition zones diameters between 24-28 $\mathrm{mm}$. The most sensitive strain was $T$. rubrum LM63, due to the essential oil has produced the largest inhibition zones with $28 \mathrm{~mm}$ diameter. The smallest inhibition zones $(24 \mathrm{~mm})$ were found to $T$. rubrum $\mathrm{LM} 333$. $\mathrm{MIC}_{50}$ and $\mathrm{MIC}_{90}$ values are also summarized in Table 1. As it can be seen, $\mathrm{MIC}_{50}$ and $\mathrm{MIC}_{90}$ for the essential oil was $312 \mu \mathrm{g} / \mathrm{mL}$ for the essayed strains. The lowest MIC value was $156 \mu \mathrm{g} / \mathrm{mL}$ for $T$. rubrum LM63, confirming the results found in the assessment of the fungal activity of the essential oil, thus these strains were the most sensitive at screening. Ketoconazole showed $\mathrm{MIC}_{50}$ and $\mathrm{MIC}_{90}$ lower than essential oil, the values found were $19.5 \mu \mathrm{g} / \mathrm{mL}$ for ketoconazole. Control results showed absence of fungal growth inhibition by Tween 80, fungal growth in broth without addition of essential oil and absence of fungal growth in broth without suspensions. The essential oil fungicide effect was stronger on T. rubrum LM63 which is shown by their lowest MFC values $(1250 \mu \mathrm{g} / \mathrm{mL}) . \mathrm{MFC}_{50}$ and $\mathrm{MFC}_{90}$ values of the oil were ever about eight times higher than MIC values for all strains tested $(2500 \mu \mathrm{g} / \mathrm{mL})$. However $\mathrm{MFC}_{50}$ and $\mathrm{MFC}_{90}$ for ketoconazole were about thirty-two times than MIC values $(625 \mu \mathrm{g} / \mathrm{mL})$.

Table 1. Antifungal activity of $C$. winterianus essential oil and ketoconazole against $T$. rubrum strains.

\begin{tabular}{|c|c|c|c|c|c|}
\hline \multirow{2}{*}{ Products } & \multirow{2}{*}{$\begin{array}{c}\text { inhibition } \\
\text { zones* }\end{array}$} & \multicolumn{2}{|c|}{$\mathrm{MIC}(\mu \mathrm{g} / \mathrm{mL})$} & \multicolumn{2}{|c|}{$\mathrm{MFC}_{50}(\mu \mathrm{g} / \mathrm{mL})$} \\
\hline & & $\mathrm{MIC}_{50}$ & $\mathrm{MIC}_{90}$ & $\mathrm{MFC}_{50}$ & $\mathrm{MFC}_{90}$ \\
\hline Essential oil & $24-28$ & 312 & 312 & 2500 & 2500 \\
\hline Ketoconazole & - & 19.5 & 19.5 & 625 & 625 \\
\hline
\end{tabular}

It is known that medicinal plants have been source of many drugs applied in clinical procedures. In nature, essential oils are involved in many important actions showing an important role in plants protection as antimicrobials and insecticides. It has long been recognized that some essential oils have antimicrobial properties and these characteristics are possibly related to the function of these compounds in plants $(2,5)$.

Earlier, this essential oil has demonstrated the antimicrobial power against various microorganisms with emphasis in protozoa, bacteria and fungi pathogenic to humans and plants, being useful for controlling mycotic diseases in large plantations, in addition to its activity as repellent and insecticide $(11,13,27,37)$. However, little information about its effect against classical important fungi involved in human infections, including dermatophytes species such as T. rubrum still exists. This fact support the importance of this study; allowing to add the antifungal action against major causative agents of dermatophytosis to the properties inherent to this essential oil.

The effects of $C$. winterianus essential oil on mycelial growth are expressed as percentage of inhibition on dry 
mycelial weight of $T$. rubrum ATCC 1683 and showed in Figure 1. This study revealed that all tested essential oil concentrations managed to inhibit the mycelium development. When analyzing each concentration separately, it is confirmed a significant statistical difference $(\mathrm{P}<0.05)$ between the results obtained only by essential oil at $156 \mu \mathrm{g} / \mathrm{mL}$, at the times of 6 , 9, 12 and 15 days. This fact confirms that in sub-inhibitory concentration, the impediment of mycelial growth of T. rubrum ATCC 1683 is getting worse with increasing interaction time between drug and fungal cells. The same information was not observed with the other essential oil concentrations, once fungus did not develop mycelium until the 15 days culture with the oil, that means $100 \%$ inhibition at all times analyzed.

Comparing the results of all concentrations tested, it was found a significant difference between 156 and 312, 625, 2500 $\mu \mathrm{g} / \mathrm{mL}$ values, at each time separately. The analysis on the essential oils effects on fungal growth in function of time used in this work has stood out among researchers around the world. Good fungal growth of Trichophyton species, similarly to other filamentous fungi, produce hyphae which can penetrate the innermost skin layer and aggravate the damage in the host (17, 43). Therefore, some researchers are investigating the essential oils potential in inhibiting mycelial growth of pathogenic fungi due to their importance in the mycosis development.

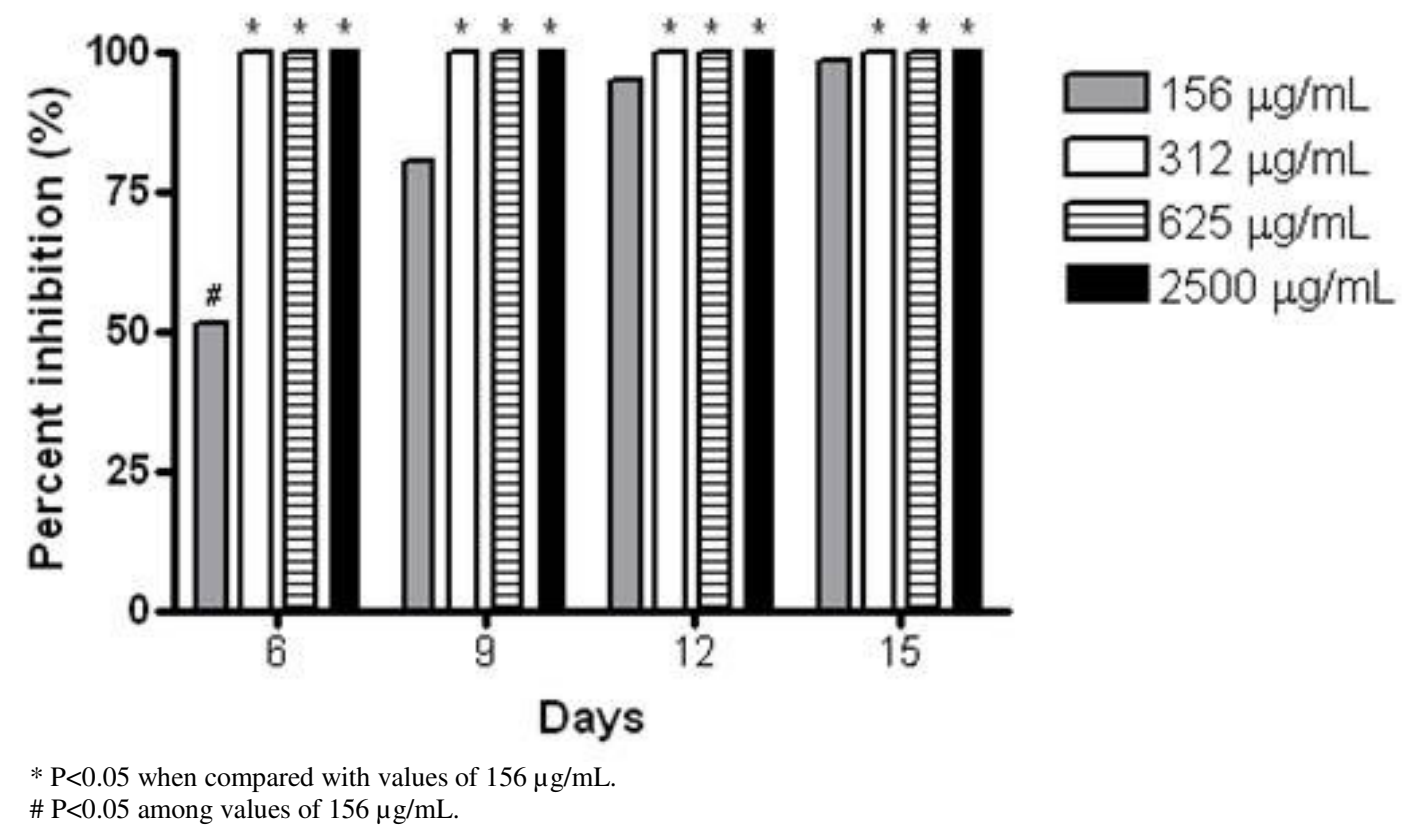

Figure 1. Percentage of inhibition on dry mycelial weight of T. rubrum ATCC 1683 in the presence of several concentrations of C. winterianus essential oil.

Observations on T. rubrum ATCC 1683, examined under light microscope at 400x magnification after exposure to $C$. winterianus essential oil, showed some morphological abnormalities. Essential oil induced similar alterations in all concentrations, however they increased in large quantities as the oil concentration increased (Figure 2). Although the form of $T$. rubrum conidia have not changed, their production was severely impaired in all essential oil concentrations making it rarely found from the $313 \mu \mathrm{g} / \mathrm{mL}$ of oil in culture medium. The vast majority of hyphae were often shorter and wider than 
normal hyphae, with losses in pigmentation and presence of vacuoles inside them. From the $156 \mu \mathrm{g} / \mathrm{mL}$ concentration, the presence of chlamydospores was detected having production increased in proportion to the increase of essential oil concentration.

Microscopic examination of the control mycelium (untreated cell) showed a regular cell structure with homogenous cytoplasm, chlamydospores absent, abundant conidiation, long clear septate hyphaes with lateral tear-shaped microconidia and macroconidia absent. Chlamydospores are usually round, increased volume and thick walled. They are formed from hyphae under unfavorable environmental conditions to fungal development. Maybe the excessive production of chlamydospores was induced by the increased oil concentration. Such phenomenon might be necessary for fungi take their growth in the presence of this adverse component. These modifications in the cytological structure may be related to the interference of the essential oil with the enzymes responsible for synthesis or maintenance of fungal cell wall as previously cited by other researchers, impairing normal growth and cell morphogenesis $(6,10,16,42)$.
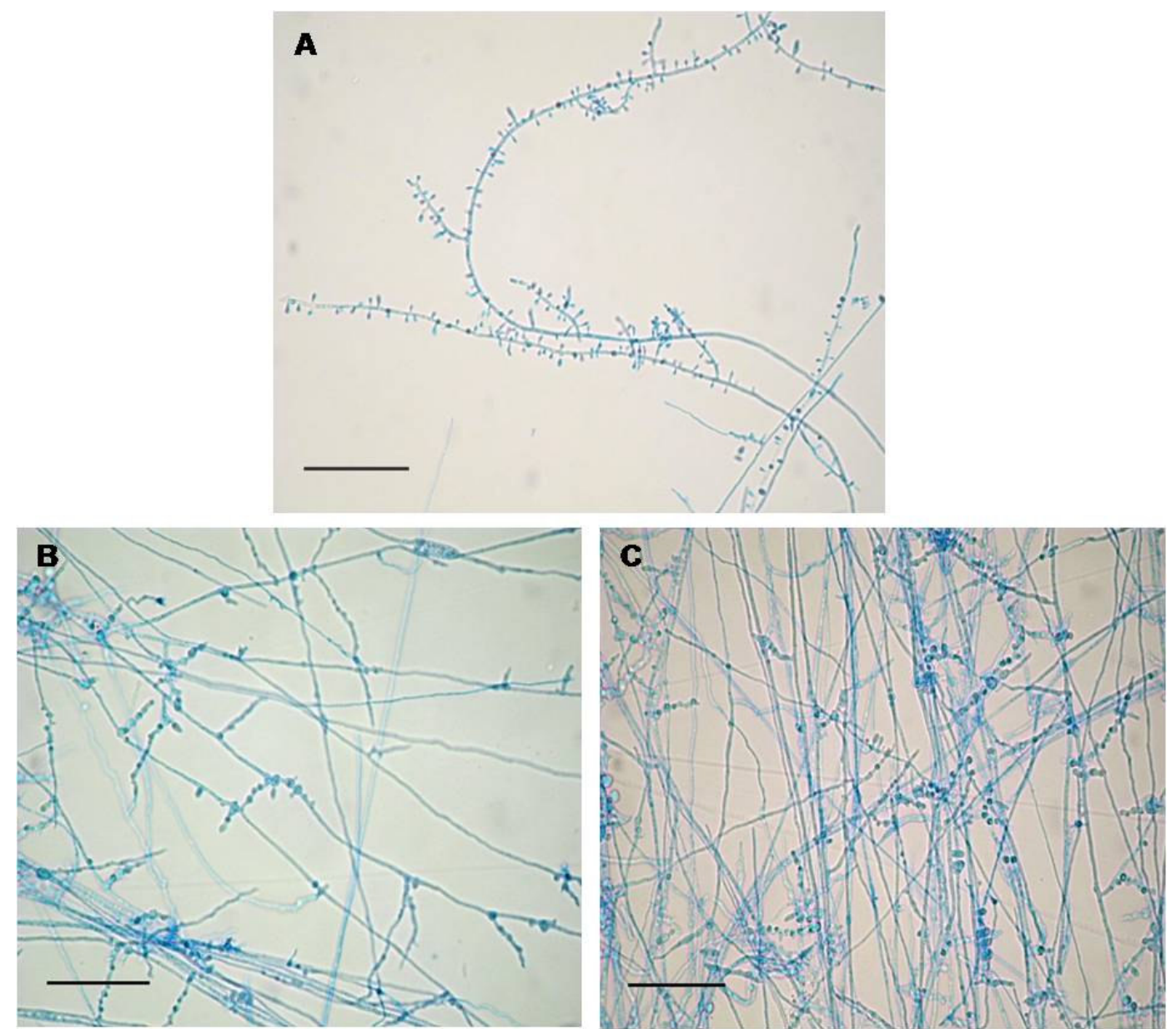

(A) Control experiment showing typical forms of species, bar $100 \mu \mathrm{m}$. (B) Modifications on hyphae development induced by essential oil $(156 \mathrm{mg} / \mathrm{mL})$ and presence of chlamydospores $(\mathrm{C})$, bar $100 \mu \mathrm{m}$.

Figure 2. Light microphotographs of T. rubrum ATCC 1683 mycelium growing on ASD without or with $C$. winterianus essential oil during 5 days incubation at $28^{\circ} \mathrm{C}$. 
The morphological evaluation of T. rubrum ATCC 1683 cultures was performed in SDA added of essential oil at 78, 156 and $312 \mu \mathrm{g} / \mathrm{mL}$ concentrations. At $78 \mu \mathrm{g} / \mathrm{mL}$ of essential oil, no visible alteration was observed in the culture. However, in presence of $156 \mu \mathrm{g} / \mathrm{mL}$ oil concentration, the colonies showed folds and a small projection in the center, cream color, slightly darker than the control, pigment production was absent on the reverse and with evident folds. In the presence of 312 $\mu \mathrm{g} / \mathrm{mL}$ essential oil, there was less colonies development and same characteristics present in concentrations above were observed. In contrast, the control experiment showed colonies with classic features of T. rubrum, with smooth velvety white colonies. The colony reverse presented no pigmentation. The results in this report direct affect on disease pathogenesis, once dermatophytosis depend on morphogenesis normal capacity of fungi and their growth in infection locus.

Essential oils of $C$. winterianus leaves have more than 80 components, but citronellal, citronellol and geraniol are terpenes cited as the mainly constituents of the oil $(4,21)$. Earlier studies reported citronellal and geraniol with antifungal activity against Aspergillus niger, Fusarium oxysporum e Penicillium digitatum, with $100 \mu \mathrm{g} / \mathrm{ml}$ MIC (20).

According to the scientific literature, the antifungal property of phytochemicals found in $C$. winterianus essential oil (e.g. mono-terpenes) involves inhibition of extracellular enzymes synthesis and the disruption of cell wall structure resulting in lack of cytoplasm, damage of integrity and ultimately the mycelial death. Damage to microorganism's membrane, collapse the proton pump, cytoplasm granulation and break down of the electron transport chain are some events possibly related to the antifungal property of essential oils (8, 36). Several records in the scientific literature worldwide reported that macromolecules found in fungi of which functionality is related to growth, survival, cell morphogenesis and virulence, are identified as promising targets for new antifungal agents (24).

Therefore, the results found in this report may be considered relevant and promising. In conclusion, this report indicates that essential oils can have a practical and rational use in the inhibition of dermatophyte growth. Even though, it is important to develop studies with the essential oil of $C$. winterianus and their isolates compounds on toxicological and pharmacological analyses for developing new antifungal agents for treatment of serious mycosis, especially the dermatophytosis.

\section{ACKNOWLEDGEMENTS}

The authors are thankful to CNPq and FAPESQ-PB for grants and fellowships.

\section{REFERENCES}

1. Adam, K.; Sivropouou, A.; Kokkini, S.; Lanaras, T.; Arsenakis, M. (1998). Antifungal activities of Origanum vulgare subsp. hirtum, Mentha spicata, Lavandula angustifólia and Slavia frticosa essential oils against human pathogenic fungi. J. Agr. Food Chem. 46 (5), 1739-1745.

2. Bakkali, F.; Averbeck, S.; Averbeck, D.; Idioomar, M. (2008). Biological effects of essential oils - A review. Food. Chem. Toxicol. 46 (2), $446-$ 475.

3. Barros, M.E.S.; Santos, D.A.; Hamdan, J.S. (2006). In vitro methods for antifungal susceptibility testing of Trichophyton spp. Mycol. Res. 110 (11), 1355-1360.

4. Blank, A.F.; Costa, A.G.; Arrigoni-Blank, M.F.; Cavalcanti, S.C.H.; Alves, P.; Innecco, R.; Ehlert, P.A.D.; Sousa, I.F. (2007). Influence of season, harvest time and drying on Java citronella (Cymbopogon winterianus Jowitt) volatile oil. Braz. J. Pharmacogn. 17 (4), 557-564.

5. Burt, S. (2004). Essential oils: their antibacterial properties and potential applications in food - a review. Int. J. Food Microbiol. 94 (3), 223-253.

6. Carmo, E.S.; Lima, E.O.; Souza, E.L.; Sousa, F.B. (2008). Effect of Cinnamomum zeylanicum Blume essential oil on the growth and morphogenesis of some potentially pathogenic Aspergillus species. Braz. J. Microbiol. 39 (1), 91-97.

7. Costa, M.; Passos, X.S.; Souza, L.K.H.; Miranda, A.T.B.; Lemos, J.A.; Oliveira Júnior, J.G.; Silva, M.R.R. (2002). Epidemiology and etiology of dermatophytosis in Goiania, GO, Brazil. Rev. Soc. Bras. Med. Trop. 35 (1), 19-22.

8. Cox, S.D.; Mann, C.M.; Markham, J.L.; Bell, H.C.; Gustafon, J.E.; Warmington, J.R.; Wyllie, S.G. (2000). The mode of antimicrobial action 
of essential oil of Melaleuca alternifolia (tea tree oil). J. Appl. Microbiol. 88 (1), 170-175.

9. Daferera, D.J.; Ziogas, B.N.; Polissiou, M.G. (2003). The effectiveness of plant essentiol oils on the grouth of Botrytis cinerca, Fusarium $s p$ and Clavibacter michiganessis. Crop Protection. 22 (1), 39-44.

10. Debilberck, V.G.; De Roques, C.G.; Bessiere, J.M.; Fonvielle, J.L.; Dargent, R. (2001). Effect of Cymbopogon nardus (L) W. Watson essential oil on the growth and morphogenesis of Aspergillus niger. C. J. Microbiol. 47 (1), 17-19.

11. De-Blasi, V.; Debrot, S.; Memoud, P.A.; Gendre, L.; Schowing, J. (1990). Amoebicidal effect of essential oils in vitro. J. Toxicol. Clin. Exp. 10 (6), 361-361.

12. Denning, D.W.; Hanson, L.H.; Perlman, A.M.; Stevens, D.A. (1992). In vitro susceptibility and synergy studies of Aspergillus species to conventional and new agents. Diag. Microbiol. Infect. Dis. 15 (1), 21-34.

13. Duarte, M.C.T.; Figueira, G.M.; Sartoratto, A.; Rehder, V.L.G.; Delarmelina, C. (2005). Anti-Candida activity of Brazilian medicinal plants. J. Ethnopharmacol. 97 (2), 305-311.

14. Frost, D.J.; Brandt, K.D.; Cugier, D.; Goldman, R.A. (1995). A wholecell Candida albicans assay for the detection of inhibitors towards fungal cell wall synthesis and assembly. J. Antibiot. 48 (4), 306-309.

15. Gräser, Y.; Kuijpers, A.F.A.; Prersber, W.; de HOOG, G.S. (2000) Molecular Taxonomy of the Trichophyton rubrum Complex. J. Clin. Microbiol. 38 (9), 3329-3336.

16. Gunji, S.; Arima, K.; Beppu, T. (1983). Screening of antifungal antibiotics according to activities inducing morphological abnormalities. Agric. Biol. Chem. 47 (9), 2061-2069.

17. Gupta, A.K.; Ahmadm I.; Porretta, M.; Summerbell, R.C. (2003). Arthroconidial formation in Trichophyton raubitschekii. Mycoses. 46 (8), 332-338.

18. Hadacek, F.; Greger, H. (2000). Testing of antifungical natural products: methodologies, comparability of results and assay choise. Phytochem. Anal. 11 (9),137-147.

19. Lima, E.O.; Gompertz, O.F.; Giesbrecht, A.M.; Paulo, M.Q. (1993). In vitro antifungal activity of essential oil obtained from officinal plants against dermatophytes. Mycoses. 36 (9-10), 333-336.

20. Lima, E. O.; Pontes, Z.B.V.S.; Oliveira, N.M.C.; Carvalho, M.F.F.P.; Guerra, M.F.L.; Santos, J.P. (1999). Frequiência de dermatofitoses em João Pessoa-Paraíba-Brasil. An. Bras Dermatol. 74 (2), 127-132.

21. Marco, C.A.; Inneccom R.; Mattos, S.H.; Borges, S.S.; Nagao, E.O (2007). Características do óleo essencial de capim-citronela em função de espaçamento, altura e época de corte. Hort. Bras. 25 (3), 429-432.

22. Moreira, A.C.P.; Lima, E.O; Wanderley, P.A.; Carmo, E.S.; Souza, E.S. (2010). Chemical composition and antifungal activity of Hyptis suaveolens (L. ) poit leaves essential oil against Aspergillus species. Braz. J. Microbiol. 41 (1), 28-33.
23. Nunes, X.P.; Maia, G.L.A.; Almeida, J.R.G.S.; Pereira, F.O.; Lima, E.O. (2006). Antimicrobial activity of the essential oil of Sida cordifolia L. Braz. J. Pharmacogn. 16 (1), 642-644.

24. Odds, F.C.; Alistair, J.P.; Gow, B.; Gow, A.R. (2003). Antifungal agents: mechanisms of action. Trends in Microbiol. 11 (6), 272-279.

25. Padilla, A.; Sampedro, A.; Sampedro, P.; Delgado, D. (2002). Clinical and epidemiological survey of dermatophytoses in Jaen (Spain). Rev. Iberoam. Micol. 19 (1), 36-39.

26. Pandey, A.K.; Rai, M. (2003). Antimycotic potential in some naturally occurring essential oils. In: Donatella, M., Raim M.(eds). Plant-derived antimycotics: current trends and future prospects. Haworth Press, London, England, p. 344-345.

27. Pattnaik, S.; Subramanyan, V.R.; Kole, C.R. (1996). Antibacterial and antifungal activity of ten essential oils in vitro. Microbios. 86 (349), 237 246.

28. Rasooli, I.; Abyaneh, M.R. (2004). Inhibitory effects of thyme oils on growth and aflatoxin production by Aspergillus parasiticus. Food Control. 15 (6), 479-483.

29. Rios, J.L.; Recio, M.C. (2005). Medicinal plants and antimicrobial activity. J. Ethnopharmacol. (perspective paper), 100 (1), 80-84.

30. Rubio, M.C.; Rezusta, A.; Tomás, J.G.; Ruesca, R.B. (1999). Perspectiva micológica de los dermatofitos en el ser humano. Rev. Iberoam. Micol. $16(1), 16-22$

31. Ruiz, L.R.B.; Zaitz, C. (2001). Dermatófitos e dermatofitoses na cidade de São Paulo no período de agosto de 1996 a julho de 1998. An. Bras. Dermatol. 76 (4), 391-401.

32. Sahin, F.; Gulluce, M.; Daferera, D.; Sokmen, A.; Polissiou, M.; Agar, G.; Ozer, H. (2004). Biological activities of the essential oil and methanol extract of Origanum vulgare ssp vulgare in the Eastern Anatolia region of Turkey. Food Control. 15 (7), 549-557.

33. Santos, D.A.; Barros, M.E.S.; Hamdan, J.S. (2006). Establishing a method of inoculum preparation for susceptibility testing of Trichophyton rubrum and Trichophyton mentagrophytes. J. Clin. Microbiol. 44 (1), 98-101.

34. Santos, D.A.; Hamdan, J.S. (2005). Evaluation of Broth Microdilution Antifungal Susceptibility Testing Conditions for Trichophyton rubrum. J. Clin. Microbiol. 43 (4), 1917-1920.

35. Sharma, N.; Tripathi, A. (2006). Effects of Citrus sinensis (L.) Osbeck epicarp essential oil on growth and morphogenesis of Aspergillus niger (L.) Van Tieghem. Microbiol. Res. 163 (3), 337-344.

36. Sikkema, J.; De Bont, J.A.M.; Poolan, B. (1995). Mechanisms of membrane toxicity of hydrocarbons. Microbiol. Rev. 59 (2), 201-222.

37. Simic, A.; Rančic, A.; Sokovic, M.D.; Ristic, M.; Grujic-Jovanovic, S.; Vukojevic, J.; Marin, P.D. (2008). Essential oil composition of Cymbopogon winterianus. and Carum carvi. and their antimicrobial activities. Pharm. Biol. 46 (6), 437-441. 
Pereira, F.O. et al.

38. Souza, E.L.; Stamford, T.L.M.; Lima, E.O.; Trajano, V.N. (2007). Effectiveness of Origanum vulgare L. essential oil to inhibit the growth of food spoiling yeasts. Food Cont. 18 (5), 409-413.

39. Squeo, R.F.; Beer, R.; Silvers, D.; Weitzman, I.; Grossman, M. (1998). Invasive Trichophyton rubrum resembling blastomycosis infection in the immunocompromised host. J. Am. Acad. Dermatol. 39 (2.2), 379-380.

40. Valdigen, G.L.; Pereira, T.; Macedo, C.; Duarte, M.L.; Oliveira, P.; Ludovico, P.; Souza-basto, A.; Leão, C.; Rodrigues, F. (2006). A twenty year survey of dermathophytoses in Braga, Portugal. Int. J. Dermatol. 45
Growth inhibition and morphological alterations of T. rubrum

(7), 822-827.

41. Weitzman, I.; Summerbell, R.C. (1995). The dermatophytes. Clin. Microbiol. Rev. 8 (2), 571-578.

42. Zambonelli, A.; Zechini D’Aurelio, A.; Bianchi, A.; Albasini, A. (1996). Effects of essential oil on phytopathogenic fungi. Phytopathol. 144 (910), 491-494.

43. Zurita, J.; Hay, R.J. (1987). Adherence of dermatophyte microconidia and arthroconidia to human keratinocytes in vitro. J. Invest. Dermatol. 89 (5), 529-534. 